\title{
Radical prostatectomy after previous transurethral resection of the prostate: a systematic review and meta-analysis
}

\author{
Huihuang Li, Cheng Zhao, Peihua Liu, Jiao Hu, Zhenglin Yi, Jinbo Chen, Xiongbing Zu \\ Department of Urology, Xiangya Hospital, Central South University, Changsha 410008, China \\ Contributions: (I) Conception and design: X Zu, J Chen, H Li; (II) Administrative support: X Zu, J Chen; (III) Provision of study material or patients: \\ X Zu, H Li, C Zhao; (IV) Collection and assembly of data: J Chen, H Li, P Liu, J Hu; (V) Data analysis and interpretation: H Li, P Liu, J Hu, Z Yi; (VI) \\ Manuscript writing: All authors; (VII) Final approval of manuscript: All authors. \\ Correspondence to: Prof. Xiongbing Zu, MD, PhD; Jinbo Chen, MD. Department of Urology, Xiangya Hospital, Central South University, Changsha \\ 410008, China. Email: zuxbxyyy@126.com; chenjinbo1989@yahoo.com.
}

\begin{abstract}
Background: The influence of a previous transurethral resection of the prostate (TURP) on the outcomes of radical prostatectomy (RP) is still controversial. Therefore, we performed a meta-analysis to evaluate the perioperative, functional and oncological outcomes of RP with or without a previous TURP.

Methods: We conducted a computerized literature search of PubMed, Embase, and the Cochrane Library and included 15 retrospective studies evaluating RPs with or without a previous TURP in this meta-analysis. Results: Fifteen studies, including 6,840 cases, were analyzed. RP after a previous TURP were related to smaller prostate volumes (WMD: $-6.93 \mathrm{~cm}^{3} ; 95 \% \mathrm{CI},-10.89$ to -2.97 ; $\mathrm{P}<0.001$ ), lower preoperative prostate-specific antigen (PSA) levels (WMD: -1.51 ; 95\% CI, -2.49 to -0.53 ; $\mathrm{P}=0.002$ ), longer operative times (WMD: $13.22 \mathrm{~min}$; 95\% CI, 4.55 to $21.89 \mathrm{~min}$; $\mathrm{P}=0.003$ ), more blood loss (WMD: $55.38 \mathrm{~mL}$; 95\% CI, 12.35 to $98.41 \mathrm{~mL} ; \mathrm{P}=0.01)$, higher overall complication rates $(\mathrm{OR}=1.98 ; 95 \% \mathrm{CI}, 1.27$ to $3.08 ; \mathrm{P}=0.002)$, longer hospital stays (WMD: 1.16 days; $95 \%$ CI, 0.65 to $1.67 ; \mathrm{P}<0.001$ ), longer duration of catheter (WMD: 0.60 days; $95 \% \mathrm{CI}, 0.56$ to $0.64 ; \mathrm{P}<0.001$ ), higher positive surgical margin rates ( $\mathrm{OR}=1.30 ; 95 \% \mathrm{CI}, 1.09$ to $1.55 ; \mathrm{P}=0.004)$, lower complete continence rates at 3 months $(\mathrm{OR}=0.67 ; 95 \% \mathrm{CI}, 0.56$ to $0.81 ; \mathrm{P}<0.001)$, 6 months $(\mathrm{OR}=0.52 ; 95 \% \mathrm{CI}, 0.31$ to $0.88 ; \mathrm{P}=0.01), 12$ months $(\mathrm{OR}=0.59 ; 95 \% \mathrm{CI}, 0.46$ to $0.74 ; \mathrm{P}<0.001)$, and lower potency rates at 12 months $(\mathrm{OR}=0.62 ; 95 \% \mathrm{CI}, 0.51$ to $0.77 ; \mathrm{P}<0.001)$. Subgroup analysis indicated that open RP after previous TURP could achieve better outcomes.

Conclusions: RP after a previous TURP leads to worse perioperative, oncological, and functional outcomes. For these patients an open procedure is recommended. Due to the low number of studies and known biases, further large-scale studies are needed to support this result.
\end{abstract}

Keywords: Prostatectomy; transurethral resection of the prostate (TURP); prostatic neoplasms; margins of excision

Submitted Jun 22, 2019. Accepted for publication Nov 05, 2019.

doi: $10.21037 /$ tau.2019.11.13

View this article at: http://dx.doi.org/10.21037/tau.2019.11.13

\section{Introduction}

Prostate carcinoma is one of the leading causes of cancerrelated deaths worldwide among older males. In 2017, approximately 164,690 American men were diagnosed with prostate carcinoma, and 29,430 will likely die from it, causing it to be a leading global health problem $(1,2)$. It is generally considered that treatment with radical prostatectomy (RP) should be recommended for locally advanced prostate carcinomas $(3,4)$. However, many older men undergo RP for locally advanced prostate carcinoma having had a previous transurethral resection of the prostate (TURP) (5), a standard surgical treatment for benign prostatic hyperplasia (BPH) (6). Some studies have shown that RP after a previous TURP was related to an increase in intraoperative 
and postoperative morbidity (7), while other studies have indicated that a RP could be safely conducted after a TURP with uncompromising results $(8,9)$. As such, the influence of a previous TURP on the outcomes of a RP is still controversial. Therefore, we performed this meta-analysis to evaluate the perioperative, functional, and oncological outcomes of a RP with or without a previous TURP.

\section{Methods}

This systematic review and meta-analysis was completed in line with the Preferred Reporting Items for Systematic Review and Meta-Analysis (PRISMA) guidelines (10) and registered on PROSPERO (http://www.crd.york.ac.uk/ PROSPERO ID: CRD42019129277).

\section{Search strategy}

We conducted a computerized literature search of PubMed, Embase, and the Cochrane Library in February 2019. The MeSH terms and their combinations were searched in [Title/Abstract] as follows: Prostatic Neoplasms, transurethral resection of prostate, and prostatectomy. We made no limitations on the publication status, but only included studies which were reported in English. If two or more studies reported on the same population, we only included the most recent.

\section{Inclusion and exclusion criteria}

Inclusion criteria: (I) studies comparing RP with or without a TURP in full text; (II) studies containing detailed information of baseline characteristics, perioperative outcomes, oncological outcomes, and functional outcomes; and (III) studies containing adequate information on estimating relative risk (RR) or hazard ratio (HR) by $95 \%$ confidence interval (95\% CI).

Exclusion criteria: (I) studies which reported mixed previous prostate surgery not confined to a transurethral resection of prostate; (II) studies not reported in English; and (III) letters to the editor, editorials, reviews, conference abstracts, case reports, and animal experimental studies.

\section{Data extraction and outcomes of interest}

Two reviewers assessed the titles and abstracts independently of all the studies, and any disagreements, were discussed and determined by a third senior reviewer. The outcomes contained four parts: baseline features, perioperative outcomes, oncological outcomes, and functional outcomes. Baseline features contained: age, prostate volumes, preoperative prostate-specific antigen (PSA) levels, body mass index (BMI), biopsy Gleason scores, and clinical stage $\geq T 3$. Perioperative outcomes contained: operative times, estimated blood loss (EBL), blood transfusion rates, complication rates, hospital stay, and duration of catheter. Oncological outcomes contained: pathologic stage $\geq \mathrm{T} 3$, pathologic Gleason scores $=7$, pathologic Gleason scores $>7$, and positive surgical margin rates. Functional outcomes included: Complete continence rates at 3, 6, and 12 months and potency rates at 12 months. We defined a RP after a previous TURP as the TURP group and a RP without a previous TURP as the non-TURP group. Most studies defined 0 or 1 safety pads used per day as complete continence $(5,8,11-15)$, except for Teber et al. and Yang et al. who defined 0 or 1 pads used per day as continence $(16,17)$, and Pastore et al. who defined an ICIQ score of <6 as continence (18). Five studies used the International Index of Erectile Function (IIEF) questionnaire and the ability to have intercourse, regardless of whether medication was used or not, to assess erectile function $(5,8,11,12,19)$. Two studies assessed erectile function only on the ability to have intercourse, regardless of whether medication was used or not $(13,16)$. Only one study assessed erectile function through the ability to have intercourse without the use of medication (14).

\section{Quality assessment and data synthesis}

We evaluated the methodological quality of all the retrospective studies based on the Newcastle-Ottawa Scale (NOS) as recommended by the Cochrane Collaboration (20). A 0 to 9 score system was applied to judge each study, and a score of 7 to 9 was considered high quality (21). Ten of the 15 studies were considered high quality.

Review Manager 5.3 (Cochrane Collaboration, Oxford, UK) was used to conduct this meta-analysis. For continuous variables, such as operative time, we applied a weighted mean difference (WMD) for comparison. While for dichotomous variables, such as complication rates, an odds ratio (OR) was applied. Both comparisons were presented with $95 \%$ confidence intervals (CIs). For any studies reporting continuous data by means and range values, we used statistical algorithms to calculate the standard deviations (22). Statistical heterogeneity was evaluated using a chi-square test with a significance level set at $\mathrm{P}<0.10$. The 


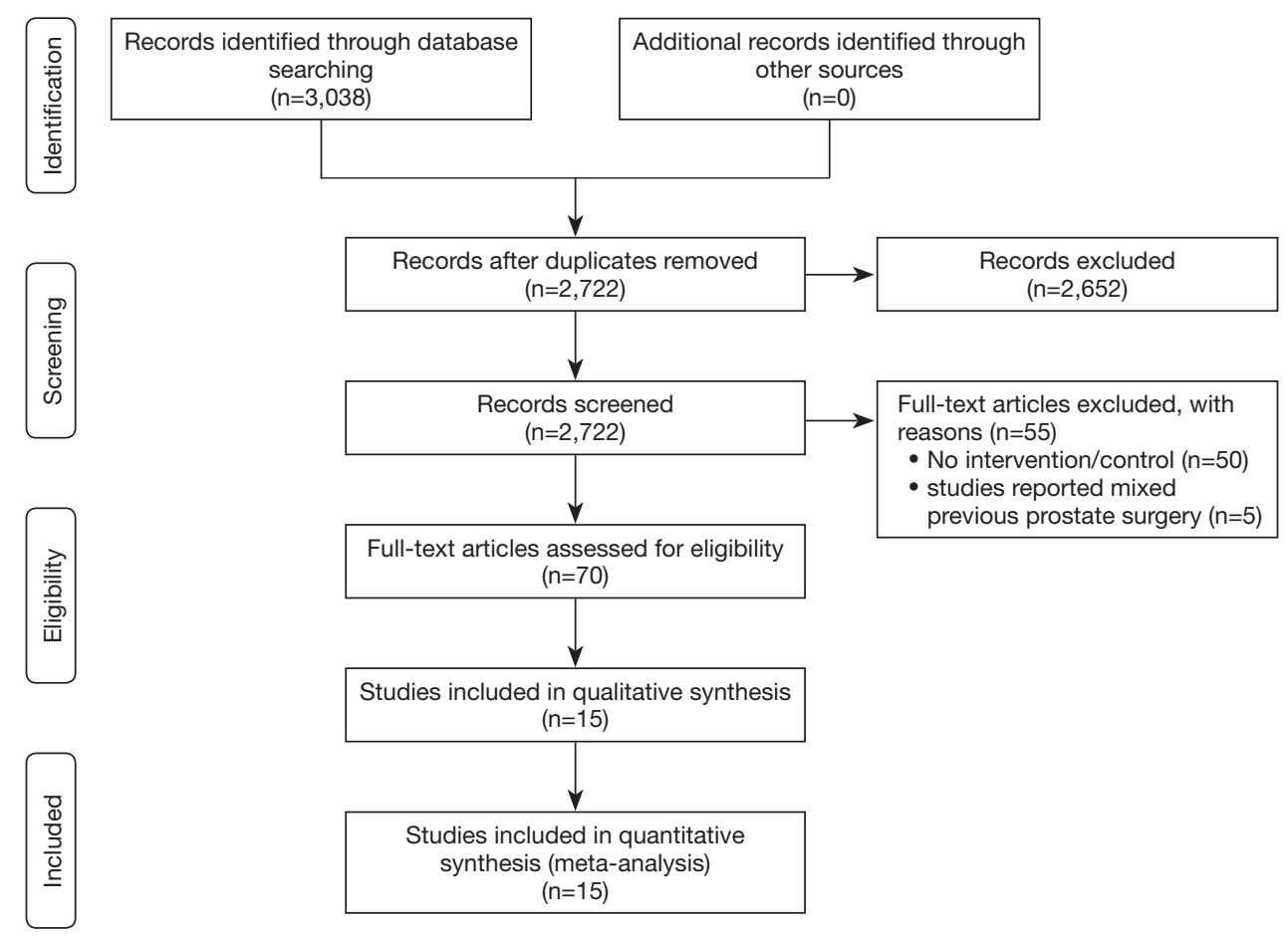

Figure 1 Flow diagram of studies identified, included, and excluded. From: Moher D, Liberati A, Tetzlaff J, et al. Preferred reporting items for systematic reviews and meta-analyses: the PRISMA statement. PLoS Med 2009;6:e1000097.

heterogeneity was quantified by the $\mathrm{I}^{2}$ statistic. If $\mathrm{P}>0.10$ and $\mathrm{I}^{2} \leq 50 \%$, heterogeneity was defined as low and a fixedeffects model was applied, alternatively, a random-effects model was applied (23). We conducted subgroup analyses to compare laparoscopic radical prostatectomy (LRP), robotic assisted laparoscopic radical prostatectomy (RARP), open prostatectomy (OP), and a mixed procedure of OP and RARP. Potential publication biases were detected using a Begg funnel plot (24).

\section{Results}

\section{Characteristics of the included studies}

Fifteen studies, including 6,840 cases $(1,121$ cases for the TURP group and 5,719 cases for the non-TURP group), met the inclusion criteria and were included in the analysis (Figure 1) (5,7,8,11-19,25-27). Study characteristics are summarized in Table 1. All 15 studies were retrospective case-controlled studies, and included 6 studies conducted by LRP (14-18,25), five studies conducted by RARP $(7,8,12,13,27)$, three studies conducted by OP $(11,19,26)$, and one study conducted by mixed procedure (5). The matching factors between the two groups were age, BMI, preoperative PSA levels, biopsy Gleason scores, prostate volumes, pathologic stage, and use of nerve sparing techniques.

\section{Baseline features}

The pooled data indicated that baseline features of age showed no significant differences between the two groups (Figure 2A). However, significantly lower prostate volumes (WMD: $-6.93 \mathrm{~mL} ; 95 \% \mathrm{CI},-10.89$ to $-2.97 ; \mathrm{P}<0.001$ ) and lower preoperative PSA levels (WMD: -1.51 ; $95 \% \mathrm{CI}$, -2.49 to $-0.53 ; \mathrm{P}=0.002$ ) were found in the TURP group. Due to the large heterogeneities, random-effect models were applied (Figure 2B,C). Other baseline features including BMI, biopsy Gleason scores, and a clinical stage sparing $\mathrm{d}$ no significant differences (Figure 3).

\section{Perioperative outcomes}

Eleven studies, including 3,697 patients, reported on operative times and demonstrated significantly longer times in the TURP group (WMD: $13.22 \mathrm{~min}$; 95\% CI, 
Table 1 Characteristics of included studies

\begin{tabular}{|c|c|c|c|c|c|c|c|c|}
\hline Study & $\begin{array}{l}\text { Level of } \\
\text { evidence }\end{array}$ & Design & Method & \multicolumn{2}{|c|}{ Patients (n) } & Matching & $\begin{array}{l}\text { Follow-up (months): } \\
\text { TURP/non-TURP1 }\end{array}$ & Quality score \\
\hline Fragkoulis & $3 b$ & $\mathrm{R}$ & OP & 35 & 35 & $1,2,3,4,5,6,7$ & $12 / 12$ & 8 \\
\hline Gupta & $3 b$ & $\mathrm{R}$ & RARP & 26 & 132 & $2,4,5,6$ & $15.3 / 15.3$ & 6 \\
\hline Hampton & $3 b$ & $\mathrm{R}$ & RARP & 51 & 102 & $1,2,3,4,6,7$ & $0 / 0$ & 7 \\
\hline Jaffe & $3 b$ & $\mathrm{R}$ & LRP & 119 & 119 & $3,4,5,6$ & $0 / 0$ & 6 \\
\hline Menard & $3 b$ & $\mathrm{R}$ & LRP & 46 & 594 & $3,4,5$ & $24 / 24$ & 6 \\
\hline Palisaar & $3 b$ & $\mathrm{R}$ & OP & 62 & 62 & $1,2,3,4,5,6,7$ & $12 / 12$ & 8 \\
\hline Paulson & $3 b$ & $\mathrm{R}$ & OP & 33 & 106 & 4 & $120 / 120$ & 5 \\
\hline Su & $3 b$ & $\mathrm{R}$ & RARP & 49 & 2,644 & $2,3,4$ & $12 / 12$ & 6 \\
\hline Teber & $3 b$ & $\mathrm{R}$ & LRP & 55 & 55 & $1,2,3,4,5,6,7$ & $24 / 24$ & 7 \\
\hline Yang & $3 b$ & $\mathrm{R}$ & LRP & 35 & 35 & $1,2,3,4,6$ & $57.6 / 57.6$ & 7 \\
\hline Zugor & $3 b$ & $\mathrm{R}$ & RARP & 80 & 80 & $1,2,3,4,5$ & $13.5 / 13.5$ & 7 \\
\hline Pastore & $3 b$ & $\mathrm{R}$ & LRP & 25 & 25 & $1,2,4,6$ & $6 / 6$ & 7 \\
\hline
\end{tabular}

TURP, radical prostatectomy after previous transurethral resection of the prostate; non-TURP, radical prostatectomy without previous transurethral resection of the prostate; R, retrospective; RARP, robotically assisted laparoscopic prostatectomy; LRP, laparoscopic prostatectomy; OP, open radical prostatectomy; Mixed, a mixed procedure of open radical prostatectomy and robotically assisted laparoscopic prostatectomy. Matching: $1=$ age; $2=$ body mass index (BMI); $3=$ prostate specific antigen (PSA); $4=$ Gleason score; $5=$ prostate volume; $6=$ pathological staging; $7=$ nerve sparing technique.

4.55 to $21.89 \mathrm{~min} ; \mathrm{P}=0.003)$. A random-effects model was applied $\left(\mathrm{I}^{2}=83 \% ; \mathrm{P}<0.001\right.$, Figure $\left.4 A\right)$. Pooled data from 10 studies included EBL for 3,542 patients and showed more significant levels of blood loss in the TURP group as compared to the non-TURP group (WMD: $55.38 \mathrm{~mL}$; $95 \% \mathrm{CI}, 12.35$ to $98.41 \mathrm{~mL} ; \mathrm{P}=0.01)$. A random-effects model was applied $\left(\mathrm{I}^{2}=83 \% ; \mathrm{P}<0.001\right.$, Figure $\left.4 B\right)$. Nine studies, including 3,041 patients, reported on transfusion rates and showed no significant differences between the two groups ( $\mathrm{OR}=1.15 ; 95 \% \mathrm{CI}, 0.83$ to $1.59 ; \mathrm{P}=0.39)$. A fixedeffects model was applied $\left(\mathrm{I}^{2}=0 \% ; \mathrm{P}=0.92\right.$, Figure $\left.4 C\right)$. Eight studies, including 3,368 patients, reported on complication rates and the pooled data showed significantly higher complication rates in the TURP group $(\mathrm{OR}=1.98 ; 95 \% \mathrm{CI}$, 1.27 to $3.08 ; \mathrm{P}=0.002)$. A random-effects model was applied $\left(\mathrm{I}^{2}=59 \% ; \mathrm{P}=0.02\right.$, Figure $\left.5 A\right)$. Three studies, including 1078 patients, reported on the length of hospital stay and indicated a significant difference between the two groups (WMD: 1.16 days; $95 \%$ CI, 0.65 to 1.67 days; $\mathrm{P}<0.001$ ).
A fixed-effects model was applied $\left(\mathrm{I}^{2}=48 \% ; \mathrm{P}=0.15\right.$, Figure 5B). Six studies, including 3,040 patients, reported on the duration of catheter use and found a significant difference between the two groups (WMD: 0.60 days; 95\% CI, 0.56 to $0.64 ; \mathrm{P}<0.001)$. A fixed-effects model was applied $\left(\mathrm{I}^{2}=0 \% ; \mathrm{P}=0.50\right.$, Figure $\left.5 \mathrm{C}\right)$.

\section{Oncological outcomes}

Pooled data indicated that the oncological outcomes of the pathologic stage $\geq T 3$, Gleason scores $=7$, and Gleason scores $>7$ showed no significant differences between the two groups (Figures 6,7A). Data from all 15 studies assessed the positive surgical margin rates of 6,840 patients, which showed significantly higher positive surgical margin rates in the TURP group than the non-TURP group $(\mathrm{OR}=1.30$; $95 \% \mathrm{CI}, 1.09$ to $1.55 ; \mathrm{P}=0.004)$ with no heterogeneity $\left(\mathrm{I}^{2}=0 \% ; \mathrm{P}=0.69\right)$, and a fixed-effects model was applied (Figure 7B). 


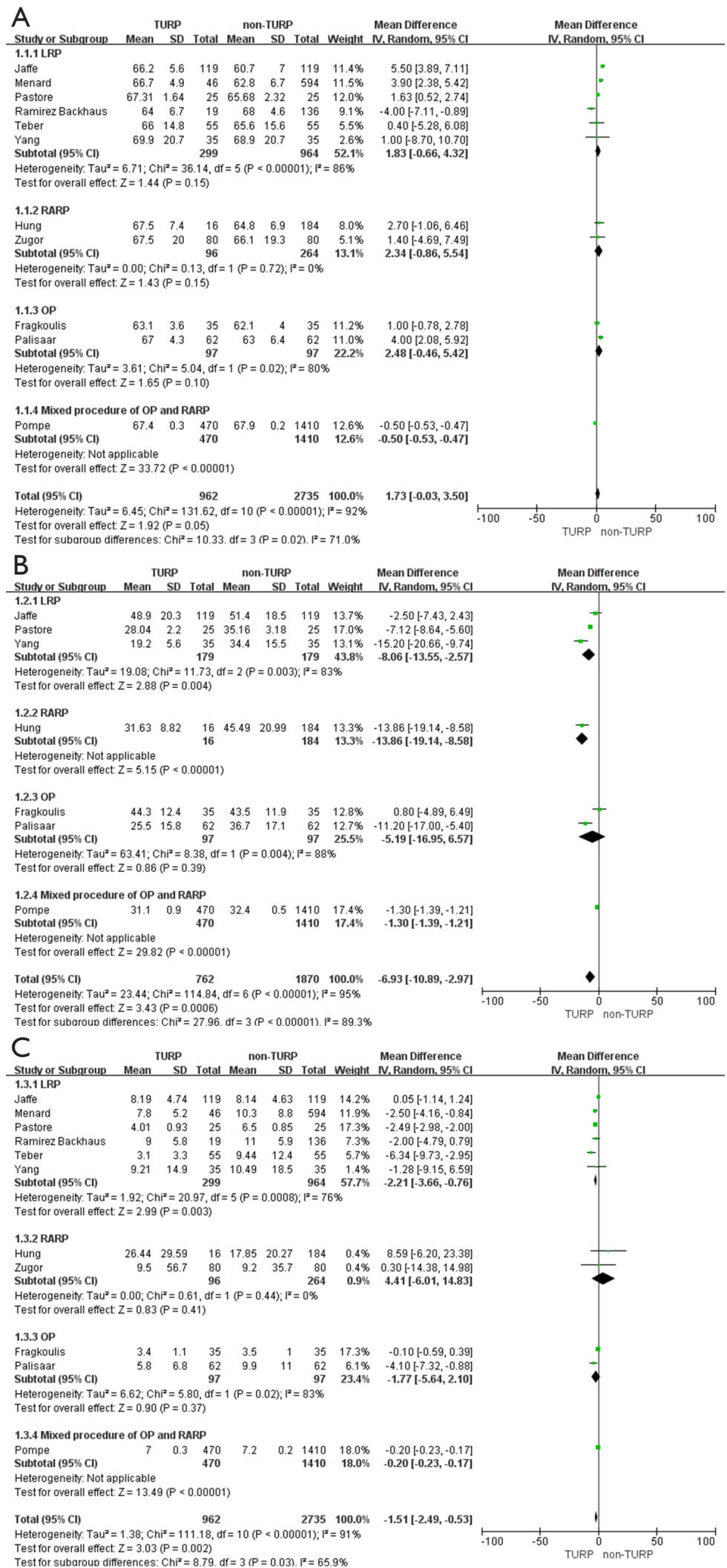

Figure 2 Forest plot for (A) age; (B) prostate volume; (C) preoperative PSA. PSA, prostate-specific antigen. 


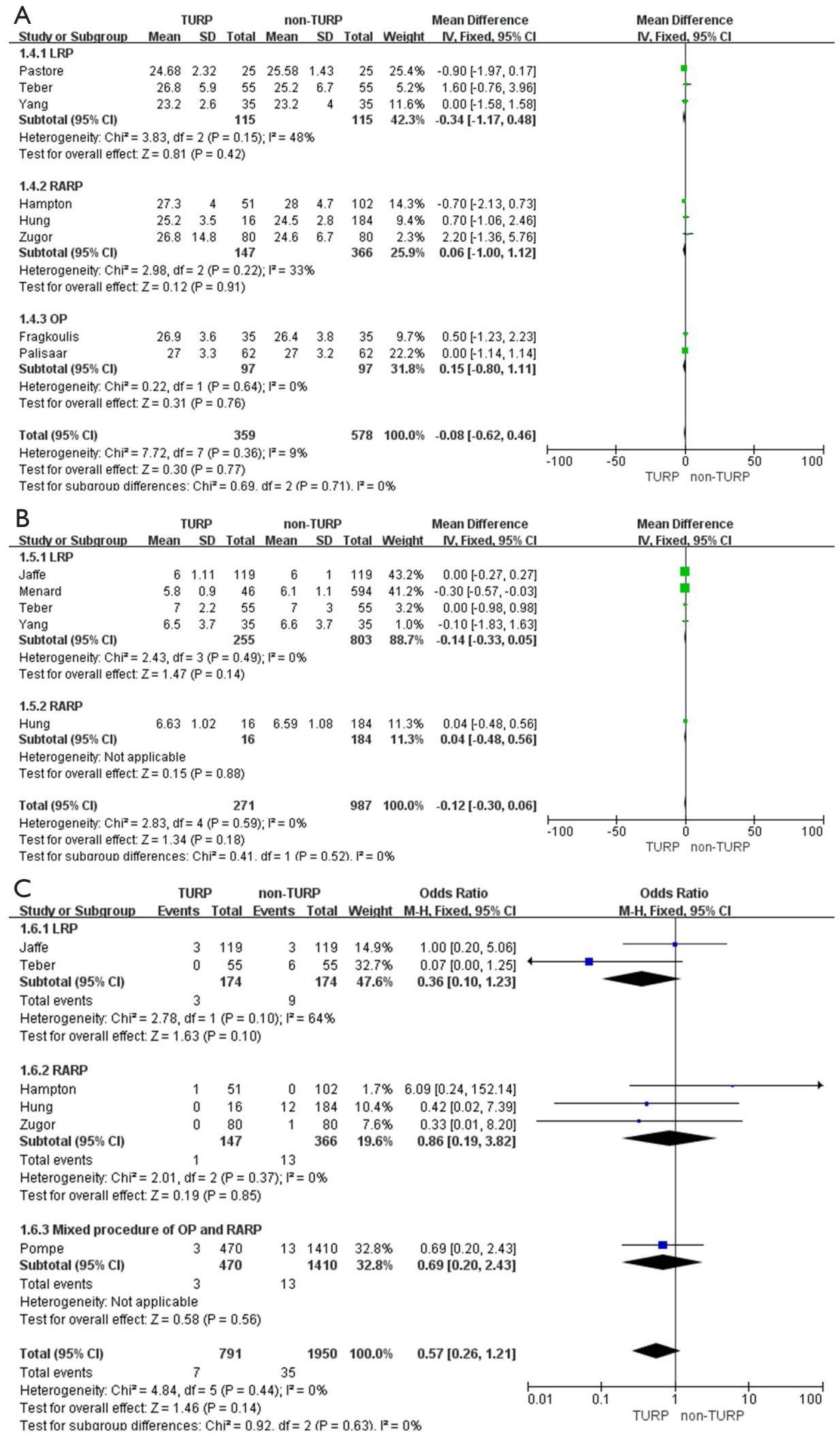

Figure 3 Forest plot for (A) BMI; (B) biopsy Gleason score; (C) clinical stage $\geq$ T3. BMI, body mass index. 


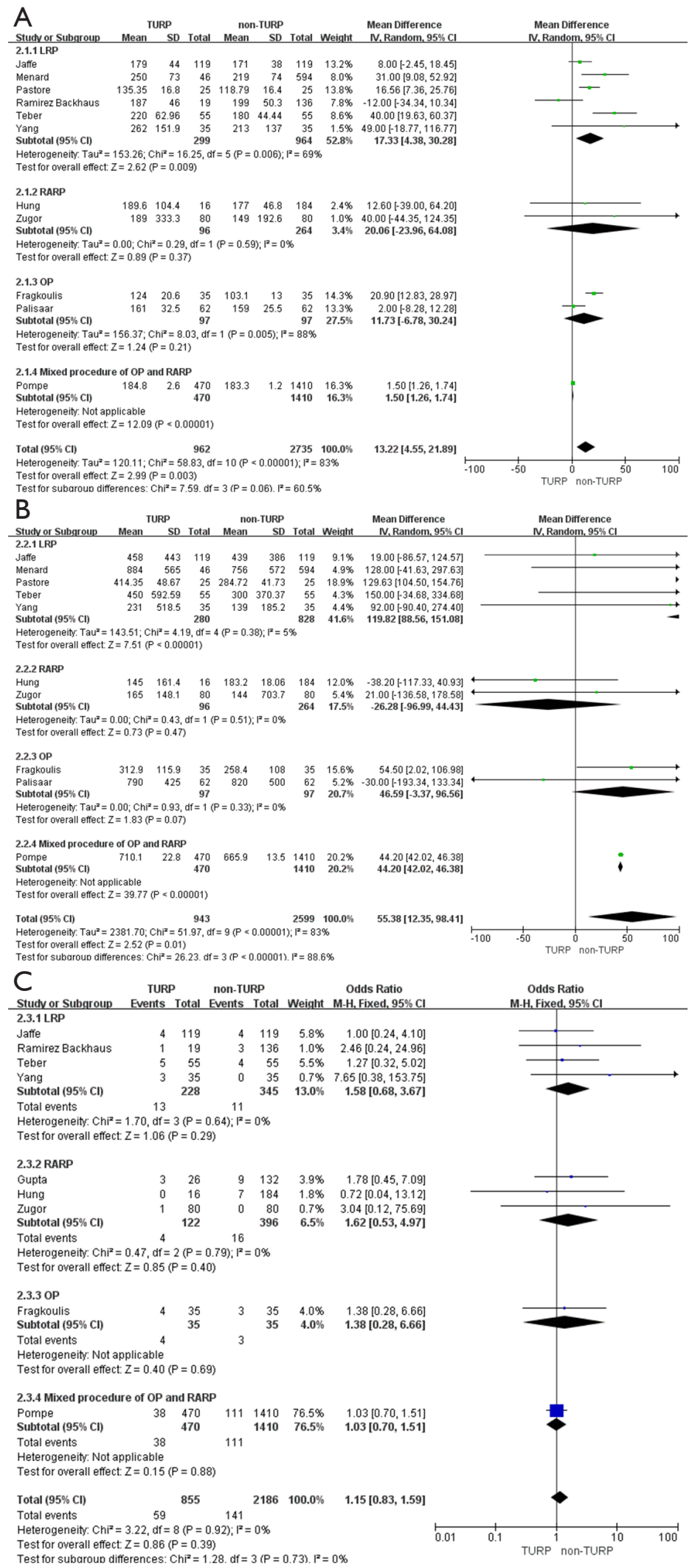

Figure 4 Forest plot for (A) operative time; (B) estimated blood loss; (C) blood transfusion rates. 


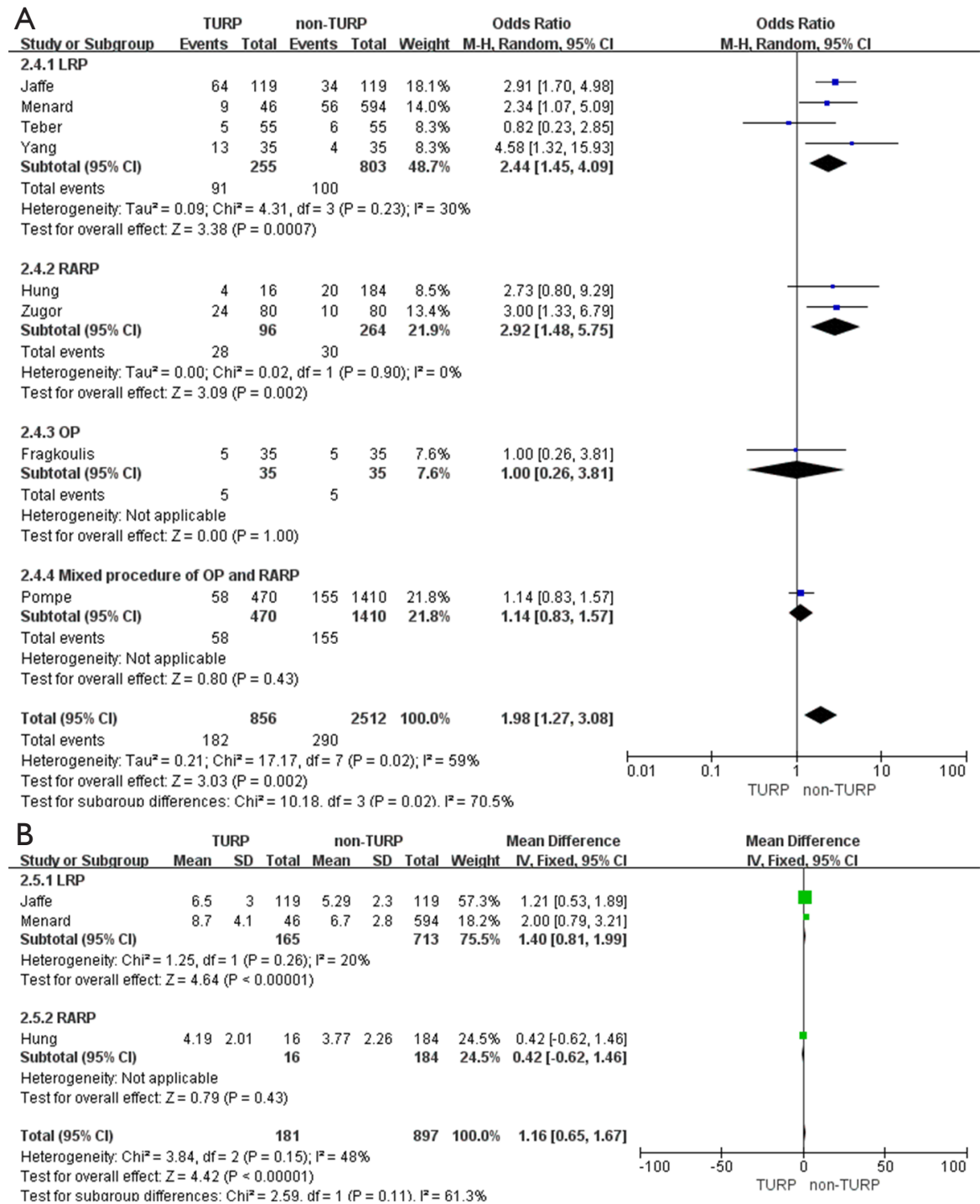

Test for subaroun differences: $\mathrm{Chi}^{2}=2.59 . \mathrm{df}=1(\mathrm{P}=0.11) \cdot \mathrm{I}^{2}=61.3 \%$

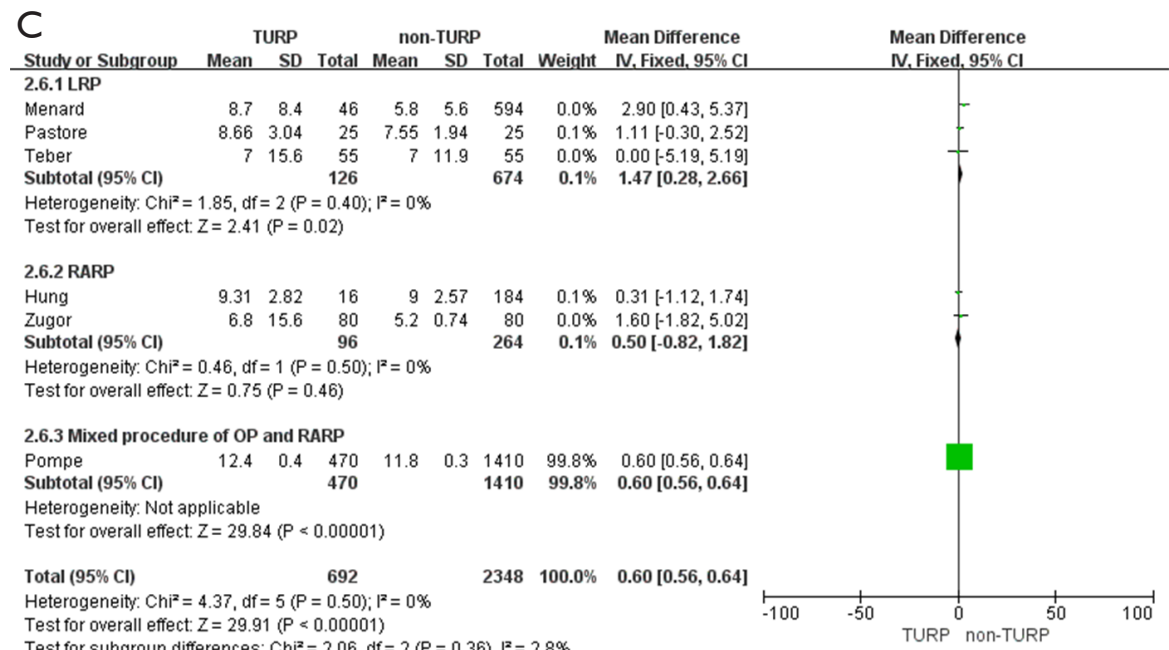

Test for subaroun differences: $\mathrm{Chi}^{2}=206 . \mathrm{df}=2(\mathrm{P}=0.36) . \mathrm{I}^{2}=28 \%$

Figure 5 Forest plot for (A) complication rates; (B) hospital stay; (C) duration of catheter. 


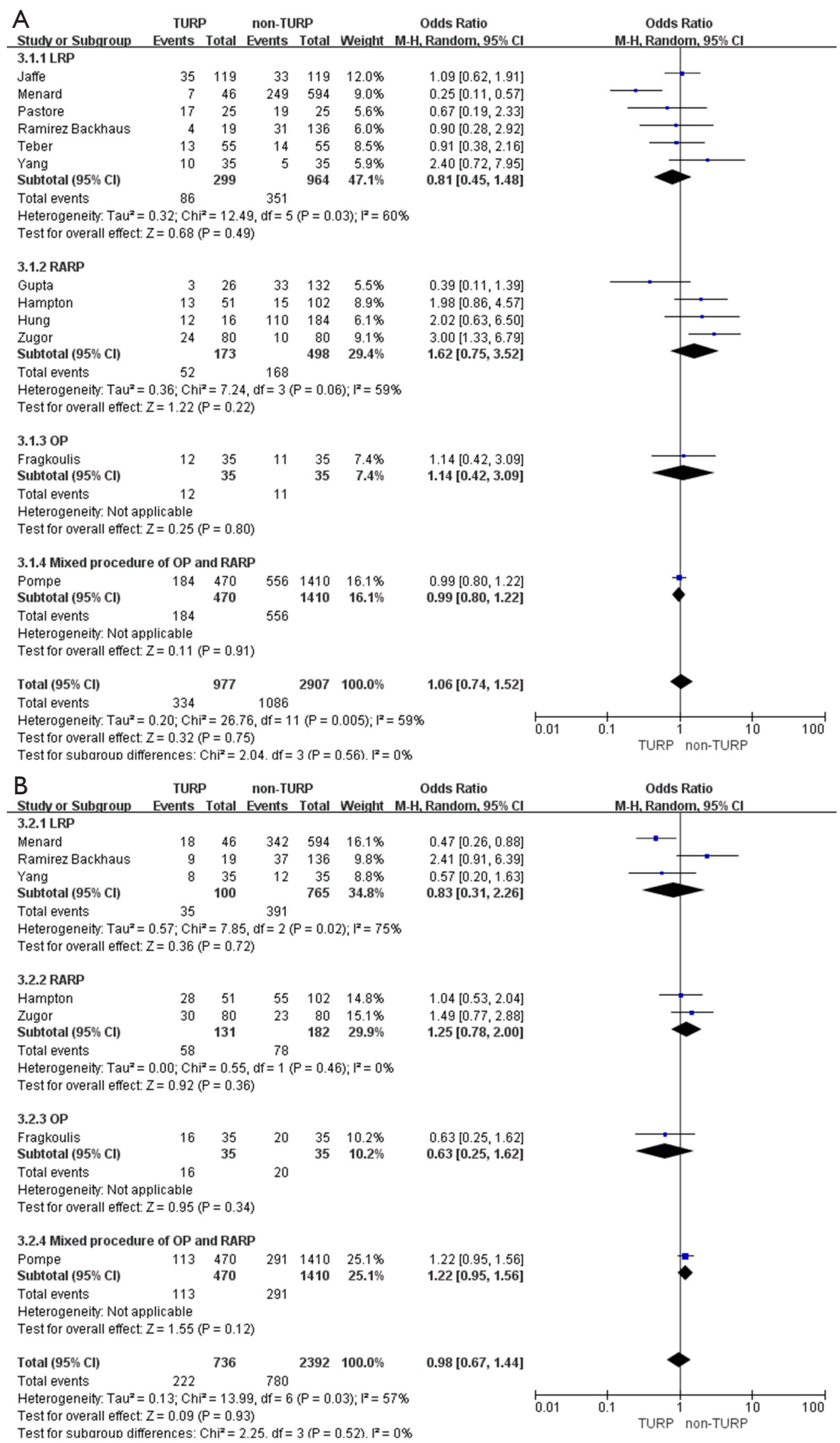

Figure 6 Forest plot for (A) pathologic stage $\geq$ T3; (B) pathologic Gleason score $=7$. 


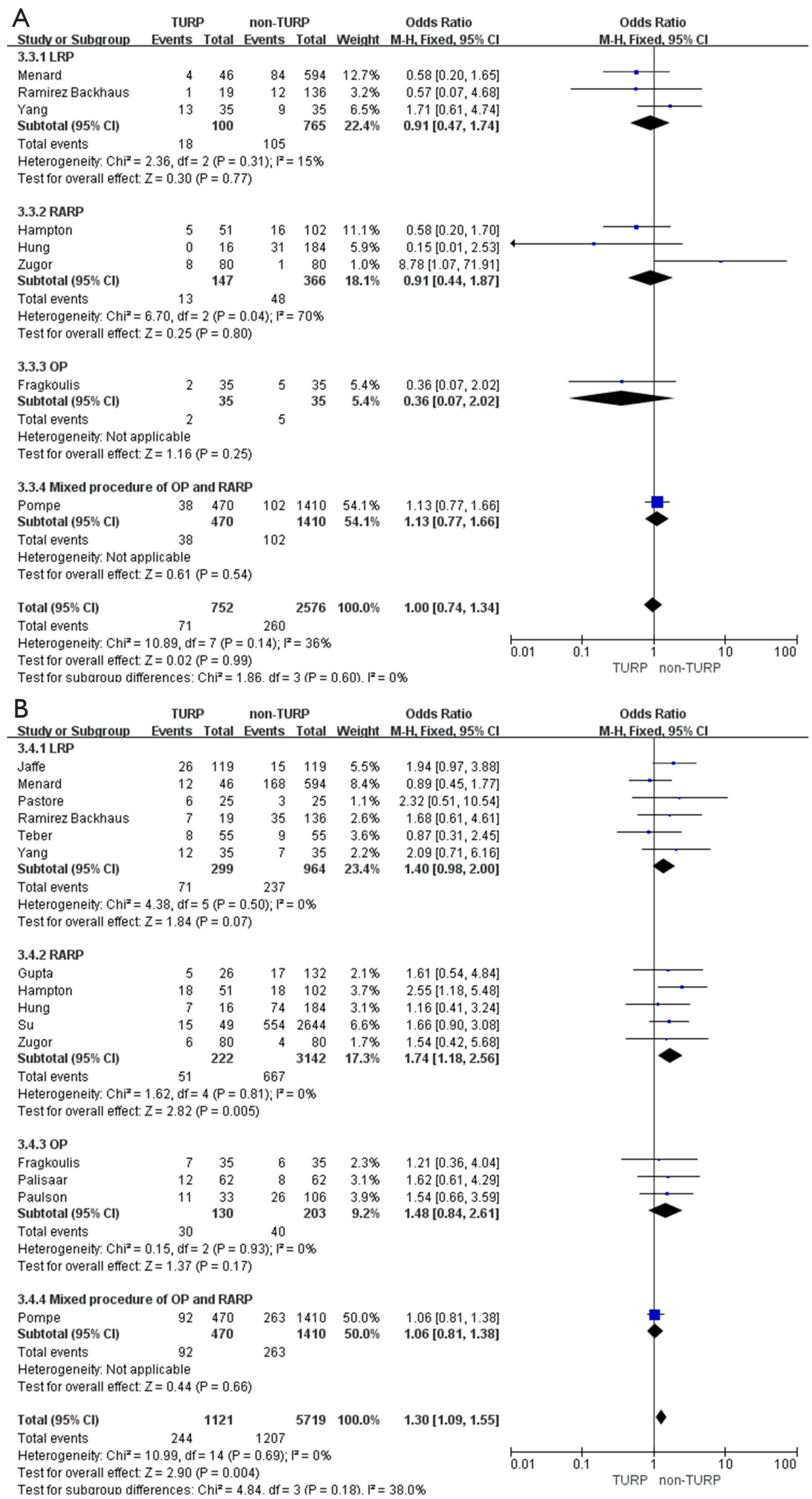

Figure 7 Forest plot for (A) pathologic Gleason score >7; (B) positive surgical margin rates. 


\section{Functional outcomes}

Pooled data from seven studies assessed the complete continence rates at 3 months for 2,625 patients, which showed significantly lower continence rates in the TURP group $(\mathrm{OR}=0.67 ; 95 \% \mathrm{CI}, 0.56$ to $0.81 ; \mathrm{P}<0.001)$. A fixedeffects model was applied $\left(\mathrm{I}^{2}=0 \% ; \mathrm{P}=0.84\right.$, Figure $\left.8 A\right)$. Pooled data from five studies assessed the complete continence rates at 6 months for 603 patients, which indicated significantly lower rates in the TURP group (OR $=0.52 ; 95 \%$ CI, 0.31 to $0.88 ; \mathrm{P}=0.01)$. A fixed-effects model was applied $\left(\mathrm{I}^{2}=0 \% ; \mathrm{P}=0.95\right.$, Figure $\left.8 B\right)$. Eight studies, including 3283 patients, evaluated the complete continence rates at 12 months and the pooled data showed significantly lower continence rates in the TURP group $(\mathrm{OR}=0.59$; 95\% CI, 0.46 to $0.74 ; \mathrm{P}<0.001)$. A fixed-effects model was applied $\left(\mathrm{I}^{2}=0 \% ; \mathrm{P}=0.93\right.$, Figure $\left.9 A\right)$. Seven studies, including 2,371 patients, evaluated the potency rates at 12 months and the pooled data showed significantly lower rates in the TURP group ( $\mathrm{OR}=0.62 ; 95 \% \mathrm{CI}, 0.51$ to $0.77 ; \mathrm{P}<0.001)$. A fixed-effects model was applied $\left(\mathrm{I}^{2}=0 \% ; \mathrm{P}=0.95\right.$, Figure $\left.9 B\right)$.

\section{Subgroup analyses}

\section{TURP group as compared with the non-TURP group} in LRP

There were no changes in this subgroup as compared with the original analysis, except for no significant differences being found in the positive surgical margin rates $(\mathrm{OR}=1.40 ; 95 \%$ $\mathrm{CI}, 0.98$ to $2.00 ; \mathrm{P}=0.07$, Figure $7 B$ ), continence rates (OR $=0.61 ; 95 \% \mathrm{CI}, 0.33$ to $1.13 ; \mathrm{P}=0.12)$, and erectile function $(\mathrm{OR}$ $=0.65 ; 95 \% \mathrm{CI}, 0.32$ to $1.35 ; \mathrm{P}=0.25$ ) at 12 months (Figure 9). Only one study reported on continence rates at 6 months, and a subgroup analysis could not be conducted.

\section{TURP group as compared with the non-TURP group in RARP}

When compared with the original analysis, no significant differences in preoperative PSA levels (WMD: 4.41; 95\% CI, -6.01 to $14.83 ; \mathrm{P}=0.41$, Figure $2 C$ ), operative times (WMD: $20.06 \mathrm{~min}$; 95\% CI, -23.96 to $64.08 \mathrm{~min} ; \mathrm{P}=0.37$, Figure $4 A$ ), EBL (WMD: $-26.28 \mathrm{~mL}$; $95 \% \mathrm{CI},-96.99$ to $44.43 \mathrm{~mL} ; \mathrm{P}=0.47$, Figure $4 B$ ), duration of catheter (WMD: 0.50 days; $95 \%$ CI, -0.82 to $1.82 ; \mathrm{P}=0.46$, Figure 5C), complete continence rates at 3 months $(\mathrm{OR}=0.56 ; 95 \% \mathrm{CI}$, 0.31 to $1.01 ; \mathrm{P}=0.06$, Figure $8 A$ ), and complete continence rates at 12 months $(\mathrm{OR}=0.53 ; 95 \% \mathrm{CI}, 0.24$ to 1.19 ; $\mathrm{P}=0.12$, Figure $9 A$ ) were found. Only one study reported on prostate volumes, biopsy Gleason scores, and hospital stay, and subgroup analyses could not be conducted.

\section{TURP group as compared with the non-TURP group in $\mathrm{OP}$}

Compared with the original analysis, no significant differences in prostate volumes (WMD: $-5.19 \mathrm{~mL}$; 95\% $\mathrm{CI},-16.95$ to $6.57 \mathrm{~mL}$; $\mathrm{P}=0.39$, Figure $2 B$ ), preoperative PSA levels (WMD: -1.77 ; 95\% CI, -5.64 to $2.10 ; \mathrm{P}=0.37$, Figure 2C), operative times (WMD: $11.73 \mathrm{~min}$; 95\% CI, -6.78 to $30.24 \mathrm{~min} ; \mathrm{P}=0.21$, Figure $4 A$ ), EBL (WMD: $46.59 \mathrm{~mL} ; 95 \% \mathrm{CI},-3.37$ to $96.56 ; \mathrm{P}=0.07$, Figure $4 B)$, positive surgical margin rates $(\mathrm{OR}=1.48 ; 95 \% \mathrm{CI}, 0.84$ to $2.61 ; \mathrm{P}=0.17$, Figure $7 B$ ), complete continence rates at 12 months $(\mathrm{OR}=0.91 ; 95 \% \mathrm{CI}, 0.40$ to $2.09 ; \mathrm{P}=0.83$, Figure $9 A)$, and potency rates at 12 months $(\mathrm{OR}=0.74$; 95\% CI, 0.31 to $1.79 ; \mathrm{P}=0.50)$ were found between the two groups (Figure 9B). Only one study reported on biopsy Gleason scores, clinical stage $\geq \mathrm{T} 3$, blood transfusion rates, complication rates, length of hospital stay, duration of catheter use, and continence rates at 3 and 6 months, and subgroup analyses could not be conducted.

\section{Quality assessment and publication bias}

The scores for the included studies are summarized in Table 1 . If the study received a score $\geq 7$, it was considered to be of high quality. Ten studies were evaluated as high quality. We used a funnel plot to assess the risk of publication bias. There was some asymmetry found (Figures S1-S4), indicating a publication bias.

\section{Discussion}

To the best of our knowledge, this systematic review and metaanalysis investigated the outcomes of a RP with or without a previous TURP for the first time. Pooled data showed that RP after a previous TURP led to worse outcomes, including perioperative, functional, and oncological outcomes. However, subgroup analyses indicated that open RP after a previous TURP could lead to better outcomes.

For the treatment management of patients with low or intermediate risk localized prostate carcinoma, a RP is believed to be a primary option (28). Whereas, for the management of BPH, a TURP is normally regarded as gold standard surgical treatment $(6,29)$. As both BPH and prostate carcinoma share age as a risk factor, there is a $4 \%$ incidence of prostate carcinoma occurring following a 


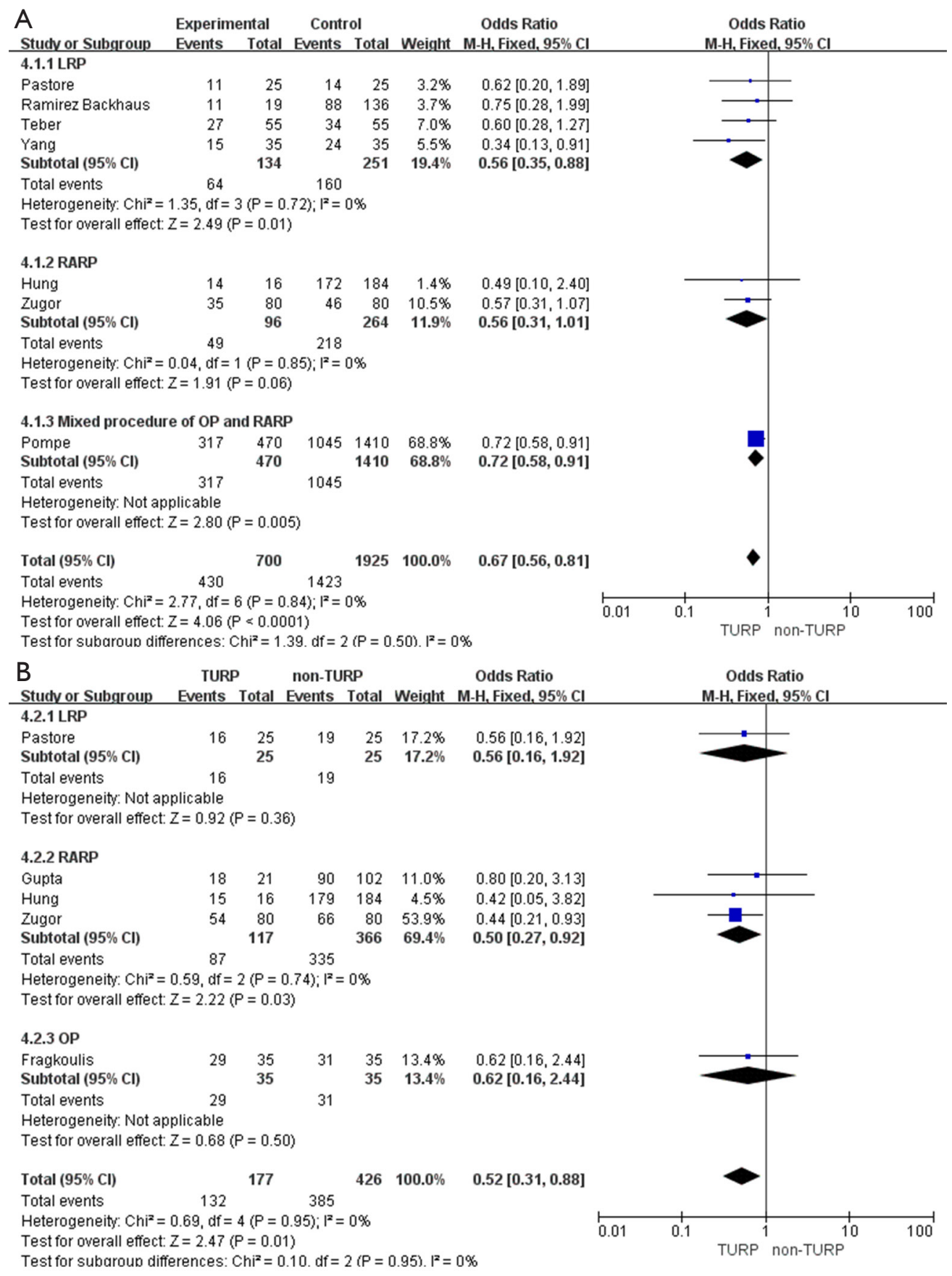

Figure 8 Forest plot for (A) continence rates at 3 months; (B) continence rates at 6 months.

TURP within a 7-year' follow-up (30). Furthermore, even after careful evaluation of PSA levels and a digital rectal examination (DRE), around $6.4 \%$ to $11.4 \%$ of patients who undergo a TURP because of bladder outlet obstruction could be diagnosed with an incidental prostate carcinoma (31-33). Unfortunately, studies investigating RP with or without a previous TURP have achieved conflicting results. Hampton et al. compared RPs in 51 patients with a previous TURP and 102 patients without a previous TURP, and concluded that patients who had received a previous TURP had higher positive margin rates (7). However, Zugor et al. performed a match-paired analysis with 160 patients 


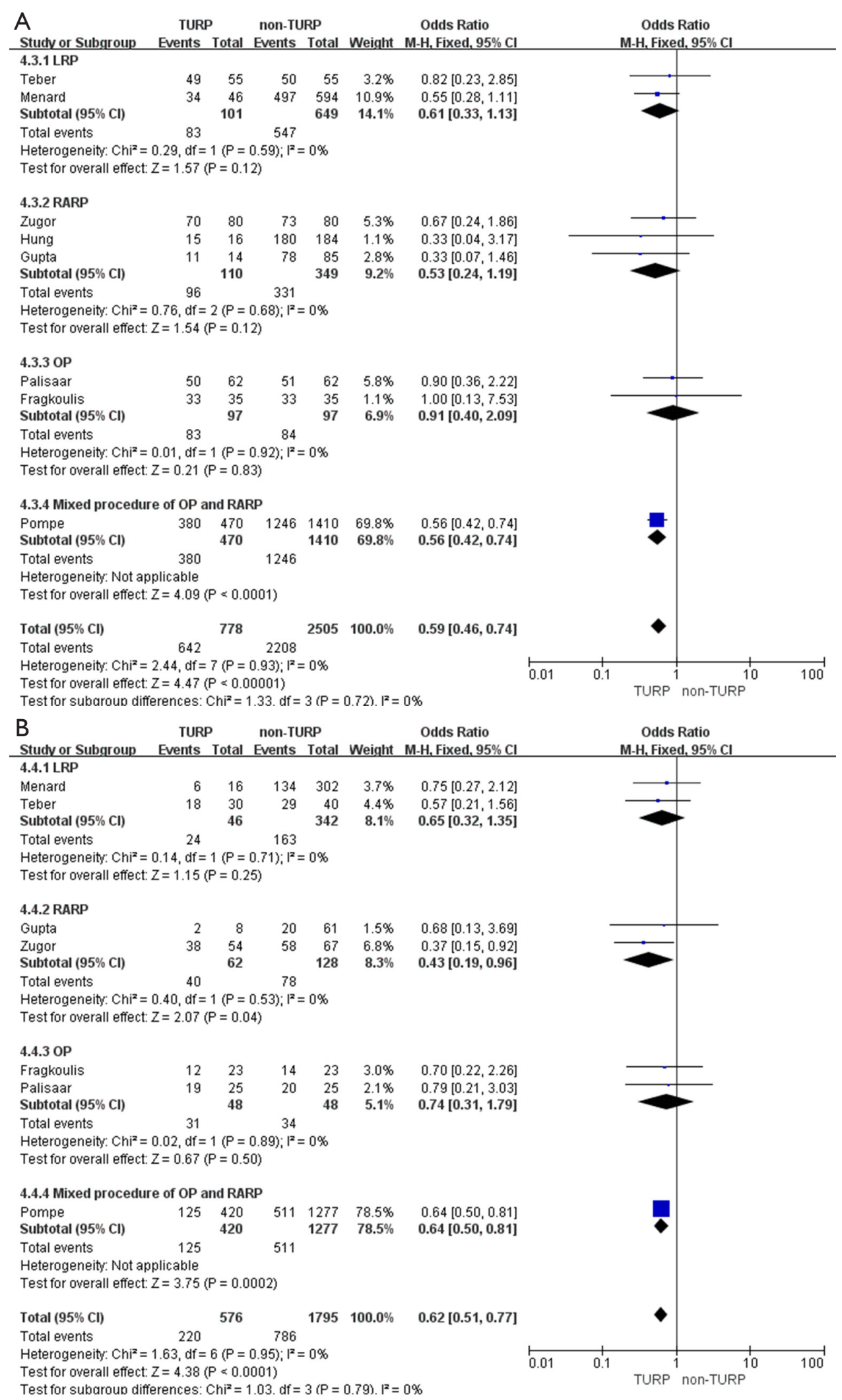

Figure 9 Forest plot for (A) continence rates at 12 months; (B) potency rates at 12 months. 
and concluded that RP could be safely conducted after a previous TURP with the same functional and oncological outcomes (8). Additionally, Do et al. conducted RPs on 100 patients who had undergone a previous TURP, which led to promising and comparable perioperative, functional, and oncological outcomes (9).

This meta-analysis of 15 retrospective studies, including 6,840 patients, which compared a RP with or without a previous TURP, showed that a RP after a TURP compromised perioperative outcomes, had longer operative times, more blood loss, higher complication rates, longer hospital stays, and a longer duration of catheter use. Furthermore, it compromised oncological outcomes, resulting in higher positive surgical margin rates, along with functional outcomes, including lower complete continence rates after 3, 6, and 12 months of follow-up and lower erectile function after 12 months of follow-up. While subgroup analyses indicated that an open RP could eliminate these differences and achieve nearly uncompromised results.

There are concerns that previous TURP could change the prostate anatomy and make a RP more challenging (11) and cause difficulties mainly concentrated on resecting the posterior bladder neck and dissecting the posterior plane of the prostate (14). A possible explanation for the compromised results is that the infection of the prostate along with the capsular perforation and extravasation of irrigation fluid during a TURP could cause periprostatic inflammation and fibrosis $(34,35)$. Additionally, after the removal of prostatic tissue, the prostatovesicular junction becomes floppy, which results in identification difficulties (12). Moreover, most of the patients underwent a previous TURP because of bladder outlet obstruction, which could thicken the bladder wall and make it difficult for urethrovesical anastomosis (17). Furthermore, for functional outcomes, identifying and preserving adequate residual urethral length are difficult as a result of the surrounding fibrosis, which may influence urethrovesical anastomosis and long-term continence. In addition, TURP can cause the internal sphincter mechanism to become deficient (17). Moreover, it is difficult to identify and preserve the neurovascular bundle because of periprostatic adhesions caused by periprostatic inflammation and fibrosis (11). However, subgroup analyses showed that an open RP could be safely and effectively performed after a previous TURP. One possible explanation is that OP can separate periprostatic inflammation and fibrosis subtly, and lead to better results.

Recently, Veccia et al. conducted a meta-analysis of LRP and RARP after previous bladder outlet surgery (BOS), and concluded that a minimally invasive RP after BOS led to worse outcomes (36). The authors recommended RARP for these patients. However, both their results and the results of this meta-analysis found no better outcomes in the RARP group. Also, they missed the study reported by Teber et al. (16). Another difference is that we only included RP after TURP. However, they included RP after TURP along with other BOS techniques, and as the authors stated, this was one of their limitations. There are also some studies which evaluated the outcomes of RP after other BOS techniques and led to conflicting results. For example, Eden et al. included 600 patients, 42 of which had undergone a previous BOS. The authors reported that previous prostate surgery resulted in similar operative times, blood loss, oncological outcomes, and functional outcomes (37). Suardi et al. evaluated the feasibility and safety of radical retropubic prostatectomy after holmium laser enucleation of the prostate (HoLEP) and concluded that a RP was feasible after a previous HoLEP (38). Martin et al. reviewed 510 patients, of which 24 patients had undergone previous treatment of the prostate, including transurethral microwave therapy, transurethral resection or incision of the prostate, photoselective vaporization, transurethral needle ablation, external beam radiotherapy, simple prostatectomy, open bladder neck reconstruction and brachytherapy. The authors concluded that a prostatic treatment history had no effect on perioperative outcomes during RARP (39). The reason for the contradictory results may be that different technologies have led to different changes in the prostate, periprostate, and bladder neck.

There are some limitations to this meta-analysis. Firstly, all the articles included were retrospective, and the number of patients was relatively small. As such, it cannot avoid selection and recall bias. Furthermore, Funnel plots indicated that there was a publication bias. Secondly, as a $\mathrm{RP}$ is a long learning curve surgery and the studies included were from all over the world, different surgeons and different centrals may have affected the outcomes. Thirdly, we could not include the time lapsed from TURP to RP within the meta-analysis, and obviously, different times could have influenced the outcomes. Finally, there was limited information on the oncological outcomes, and longterm follow-up of the patient's biochemical recurrence and overall survival are needed.

\section{Conclusions}

This meta-analysis suggests that RP after a previous TURP 
leads to worse perioperative, oncological, and functional outcomes. For these patients, an open procedure should instead be recommended. Due to the low number of studies and the known bias, further large-scale studies are needed to support this result.

\section{Acknowledgments}

Funding: This work supported by the National Natural Science Foundation of China [81572523, 81700665], the Hunan Province Funds for Distinguished Young Scientists of China [2016JJ1026].

\section{Footnote}

Conflicts of Interest: The authors have no conflicts of interest to declare.

Ethical Statement: The authors are accountable for all aspects of the work in ensuring that questions related to the accuracy or integrity of any part of the work are appropriately investigated and resolved. This article does not contain human participants or animals.

\section{References}

1. He K, Hu H, Ye S, et al. The effect of metformin therapy on incidence and prognosis in prostate cancer: A systematic review and meta-analysis. Sci Rep 2019;9:2218.

2. Lim E. Prostate-specific membrane antigen in prostate cancer imaging and treatment. Transl Cancer Res 2018;7:S676-89.

3. Mikkilineni N, Hyams ES. Neoadjuvant therapies for surgical management of high-risk, localized prostate cancer. Transl Cancer Res 2018;7:S662-75.

4. Saika T, Miura N, Fukumoto T, et al. Role of robotassisted radical prostatectomy in locally advanced prostate cancer. Int J Urol 2018;25:30-5.

5. Pompe RS, Leyh-Bannurah SR, Preisser F, et al. Radical prostatectomy after previous TUR-P: Oncological, surgical, and functional outcomes. Urol Oncol 2018;36: 527.e21-527.e28.

6. Liao J, Zhang X, Chen M, et al. Transurethral resection of the prostate with preservation of the bladder neck decreases postoperative retrograde ejaculation. Wideochir Inne Tech Maloinwazyjne 2019;14:96-101.

7. Hampton L, Nelson RA, Satterthwaite R, et al. Patients with prior TURP undergoing robot-assisted laparoscopic radical prostatectomy have higher positive surgical margin rates. J Robot Surg 2008;2:213-6.

8. Zugor V, Labanaris AP, Porres D, et al. Surgical, oncologic, and short-term functional outcomes in patients undergoing robot-assisted prostatectomy after previous transurethral resection of the prostate. Journal of Endourology 2012;26:515-9.

9. Do M, Haefner T, Liatsikos E, et al. Endoscopic Extraperitoneal Radical Prostatectomy After Previous Transurethral Resection of Prostate: Oncologic and Functional Outcomes of 100 Cases. Urology 2010;75:1348-52.

10. Liberati A, Altman DG, Tetzlaff J, et al. The PRISMA statement for reporting systematic reviews and metaanalyses of studies that evaluate healthcare interventions: explanation and elaboration. BMJ 2009;339:b2700.

11. Fragkoulis C, Pappas A, Theocharis G, et al. Open radical prostatectomy after transurethral resection: perioperative, functional, oncologic outcomes. Can J Urol 2018;25:9262-7.

12. Gupta NP, Singh P, Nayyar R. Outcomes of robot-assisted radical prostatectomy in men with previous transurethral resection of prostate. BJU Int 2011;108:1501-5.

13. Hung CF, Yang CK, Ou YC. Robotic assisted laparoscopic radical prostatectomy following transurethral resection of the prostate: perioperative, oncologic and functional outcomes. Prostate Int 2014;2:82-9.

14. Menard J, de la Taille A, Hoznek A, et al. Laparoscopic Radical Prostatectomy After Transurethral Resection of the Prostate: Surgical and Functional Outcomes. Urology 2008;72:593-7.

15. Ramírez Backhaus M, Juan Escudero J, Palmero Marti JL, et al. Importance of previous transurethral resection of the prostate before eerpe.short-term functional outcomes in a single surgeon series. Arch Esp Urol 2012;65:675-83.

16. Teber D, Cresswell J, Ates M, et al. Laparoscopic radical prostatectomy in clinical T1a and $\mathrm{T} 1 \mathrm{~b}$ prostate cancer: oncologic and functional outcomes--a matched-pair analysis. Urology 2009;73:577-81.

17. Yang Y, Luo Y, Hou GL, et al. Laparoscopic Radical Prostatectomy after Previous Transurethral Resection of the Prostate in Clinical T1a and T1b Prostate Cancer: A Matched-Pair Analysis. Urol J 2015;12:2154-9.

18. Pastore AL, Palleschi G, Silvestri L, et al. Laparoscopic radical prostatectomy after previous transurethral resection of prostate using a catheter balloon inflated in prostatic urethra: Oncological and functional outcomes from a matched pair analysis. Int J Urol 2015;22:1037-42. 
19. Palisaar JR, Wenske S, Sommerer F, et al. Open radical retropubic prostatectomy gives favourable surgical and functional outcomes after transurethral resection of the prostate. BJU Int 2009;104:611-5.

20. Lo CK, Mertz D, Loeb M. Newcastle-Ottawa Scale: comparing reviewers' to authors' assessments. BMC Med Res Methodol 2014;14:45.

21. Cao J, Liu J, Xu R, et al. Prognostic role of tumourassociated macrophages and macrophage scavenger receptor 1 in prostate cancer: a systematic review and meta-analysis. Oncotarget 2017;8:83261-9.

22. Hozo SP, Djulbegovic B, Hozo I. Estimating the mean and variance from the median, range, and the size of a sample. BMC Med Res Methodol 2005;5:13.

23. Cui Y, Chen H, Liu L, et al. Comparing the Efficiency and Safety of Bipolar and Monopolar Transurethral Resection for Non-Muscle Invasive Bladder Tumors: A Systematic Review and Meta-Analysis. J Laparoendosc Adv Surg Tech A 2016;26:196-202.

24. Egger M, Davey Smith G, Schneider M, et al. Bias in meta-analysis detected by a simple, graphical test. BMJ 1997;315:629-34.

25. Jaffe J, Stakhovsky O, Cathelineau X, et al. Surgical Outcomes for Men Undergoing Laparoscopic Radical Prostatectomy After Transurethral Resection of the Prostate. J Urol 2007;178:483-7.

26. Paulson DF, Cox EB. Does transurethral resection of the prostate promote metastatic disease? J Urol 1987;138:90-1.

27. Su YK, Katz BF, Sehgal SS, et al. Does previous transurethral prostate surgery affect oncologic and continence outcomes after RARP? J Robot Surg 2015;9:291-7.

28. Huang Z, Yi L, Zhong Z, et al. Comparison of FastTrack Versus Conventional Surgery Protocol for Patients Undergoing Robot-Assisted Laparoscopic Radical Prostatectomy: A Chinese Experience. Sci Rep 2018;8:8017.

29. Zhang X, Zeng X, Dong L, et al. The effects of statins on benign prostatic hyperplasia in elderly patients with metabolic syndrome. World J Urol 2015;33:2071-7.

30. Kanno H, Umemoto S, Izumi K, et al. Prostate

Cite this article as: $\mathrm{Li} \mathrm{H,} \mathrm{Zhao} \mathrm{C,} \mathrm{Liu} \mathrm{P,} \mathrm{Hu} \mathrm{J,} \mathrm{Yi} \mathrm{Z,} \mathrm{Chen}$ J, Zu X. Radical prostatectomy after previous transurethral resection of the prostate: a systematic review and metaanalysis. Transl Androl Urol 2019;8(6):712-727. doi: 10.21037/ tau.2019.11.13 cancer development after transurethral resection of the prostate--histopathological studies of radical prostatectomy specimens. Nihon Hinyokika Gakkai Zasshi 2006;97:649-59.

31. Zigeuner RE, Lipsky K, Riedler I, et al. Did the rate of incidental prostate cancer change in the era of PSA testing? A retrospective study of 1127 patients. Urology 2003;62:451-5.

32. Bright EA, Manuel C, Goddard JC, et al. Incidence and factors predicting the detection of prostate cancer after transurethral resection of the prostate for clinically benign disease. Urol Int 2009;83:171-4.

33. Antunes AA, Freire Gde C, Aiello Filho D, et al. Analysis of the risk factors for incidental carcinoma of the prostate in patients with benign prostatic hyperplasia. Clinics (Sao Paulo) 2006;61:545-50.

34. Ramon J, Rossignol G, Leandri P, et al. Morbidity of radical retropubic prostatectomy following previous prostate resection. J Surg Oncol 1994;55:14-9.

35. Colombo R, Naspro R, Salonia A, et al. Radical prostatectomy after previous prostate surgery: clinical and functional outcomes. J Urol 2006;176:2459-63; discussion 2463.

36. Veccia A, Antonelli A, Francavilla S, et al. Minimally Invasive Radical Prostatectomy After Previous Bladder Outlet Surgery: A Systematic Review And Pooled Analysis Of Comparative Studies. J Urol 2019;202:511-7.

37. Eden CG, Richards AJ, Ooi J, et al. Previous bladder outlet surgery does not affect medium-term outcomes after laparoscopic radical prostatectomy. BJU International 2007;99:399-402.

38. Suardi N, Scattoni V, Briganti A, et al. Nerve-sparing radical retropubic prostatectomy in patients previously submitted to holmium laser enucleation of the prostate for bladder outlet obstruction due to benign prostatic enlargement. Eur Urol 2008;53:1180-5.

39. Martin AD, Desai PJ, Nunez RN, et al. Does a history of previous surgery or radiation to the prostate affect outcomes of robot-assisted radical prostatectomy? BJU Int 2009;103:1696-8. 

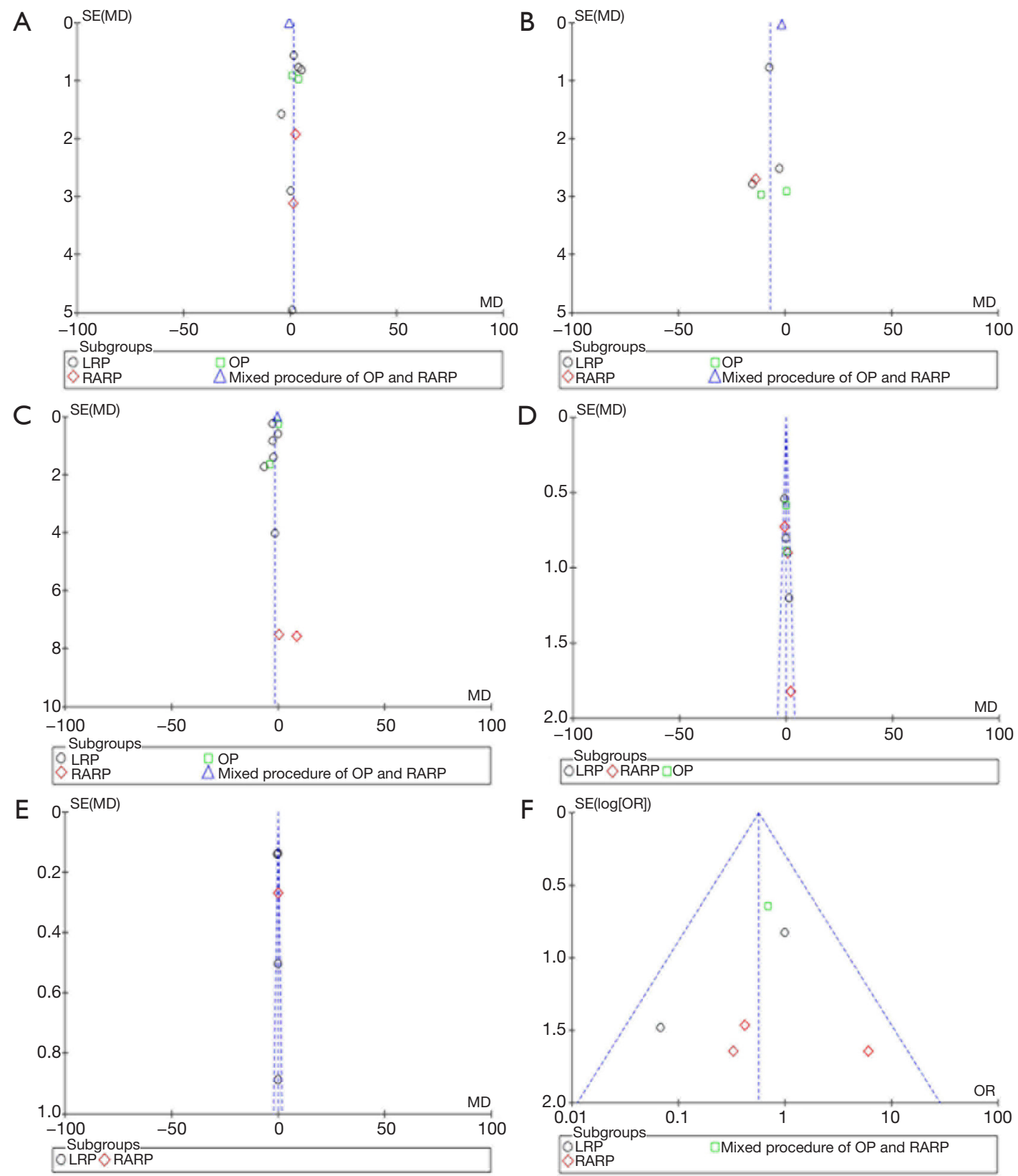

Figure S1 Funnel plots for (A) age; (B) prostate volume; (C) preoperative PSA; (D) BMI; (E) biopsy Gleason score; (F) clinical stage $\geq$ T3. BMI, body mass index. 

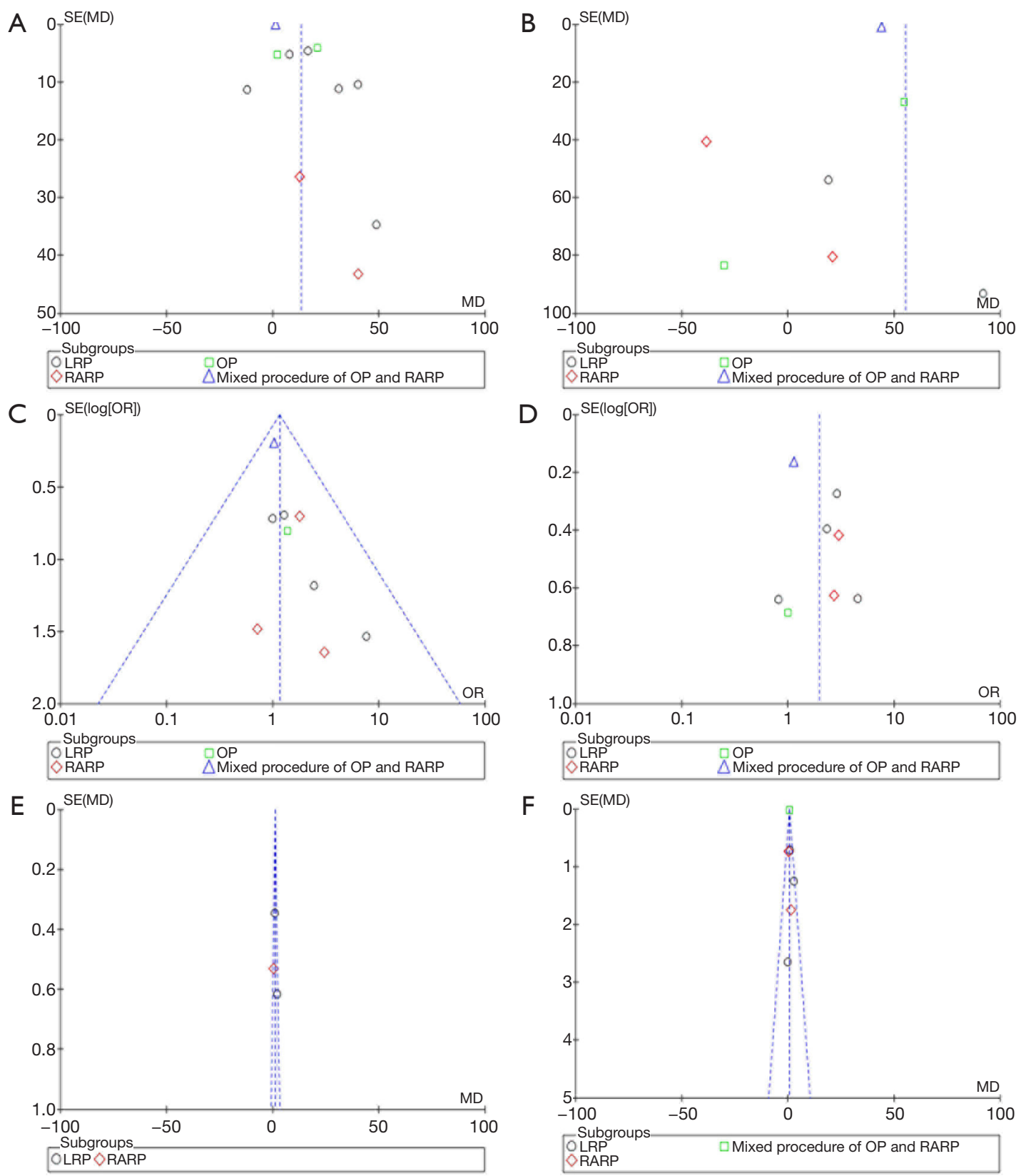

Figure S2 Funnel plots for (A) operative time; (B) estimated blood loss; (C) blood transfusion rates; (D) complication rates; (E) hospital stay; (F) duration of catheter. 

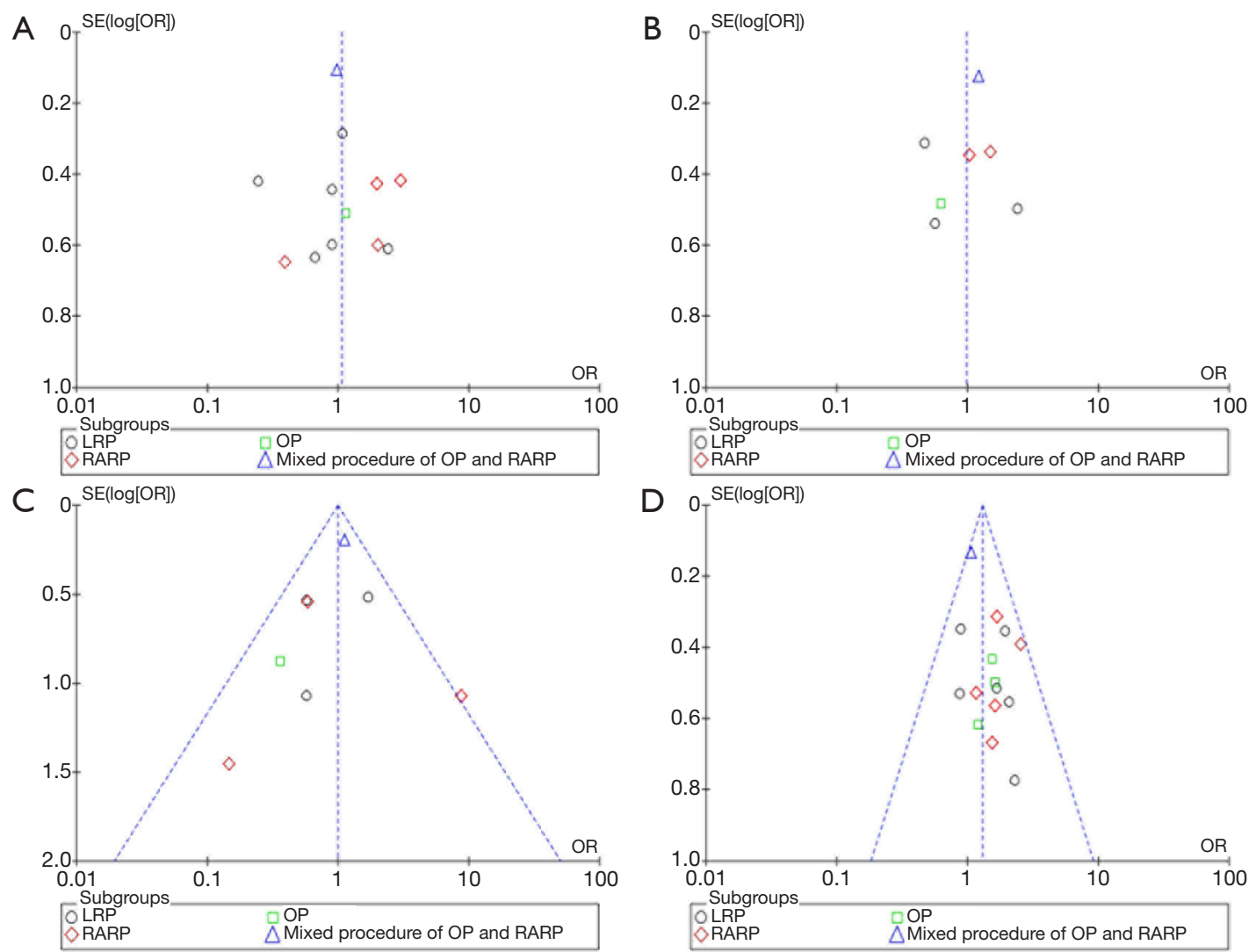

Figure S3 Funnel plots for (A) pathologic stage $\quad \geq$ T3; (B) pathologic Gleason score =7; (C) pathologic Gleason score >7; (D) positive surgical margin rates. 

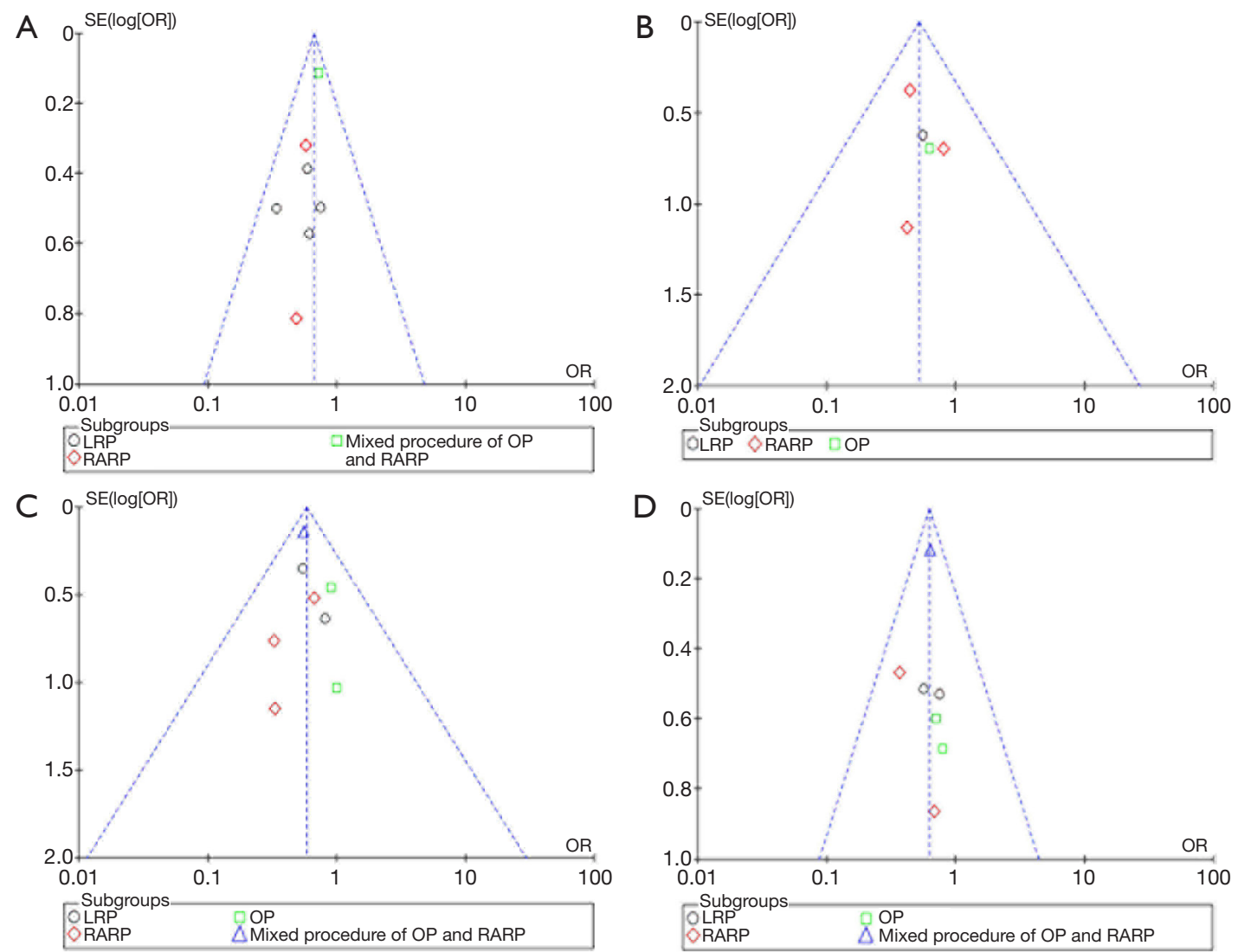

Figure S4 Funnel plots for (A) continence rates at 3 months; (B) continence rates at 6 months; (C) continence rates at 12 months; (D) potency rates at 12 months. 